Revista Española de Antropología Americana ISSN: 0556-6533

https://doi.org/10.5209/REAA.61978

\title{
El empleo de fotogrametría mediante vehículos aéreos no tripulados (VANT/dron) como herramienta de evaluación del patrimonio en riesgo: chinampas arqueológicas de Xochimilco
}

\author{
Guillermo Acosta ${ }^{1}$, Emily McClung ${ }^{2}$, Gerardo Jiménez ${ }^{3}$ y Víctor Hugo García ${ }^{4}$
}

Recibido: 10 de octubre de 2017 / Aceptado: 30 de octubre de 2017

Resumen. El desarrollo de la tecnología de vehículos aéreos no tripulados (VANT, dron) en la última década ha sido vertiginoso. Su empleo en el estudio del patrimonio cultural es creciente y en este estudio exponemos un flujo de trabajo empleando un sistema automatizado de registro por fotografía aérea mediante el uso de un dispositivo que integra un hexacóptero al que se le han adaptado dos cámaras fotográficas, una de ellas para obtener imágenes de luz visible (VIS) y otra modificada para captar el infrarrojo. Hemos tomado como estudio de caso un sitio chinampero en Xochimilco (El Japón) para evaluar su utilidad en el registro y reconocimiento de rasgos enterrados a escasa profundidad. Mediante el procesamiento fotogramétrico de los estereopares se generó el modelo digital de elevación para registra una topografía de alta resolución similar a la obtenida mediante un LIDAR, así como otras una imágenes en composición de falso color para la creación de mapas de índice de vegetación diferencial normalizada (NDVI) que permiten resaltar rasgos arqueológicos con base en diferencias del crecimiento y vigor de la vegetación.

Palabras clave: Drones, Patrimonio Cultural, Xochimilco.

\section{[en] Using Photogrammetry through Unmanned Aerial Vehicles (UAV) as a Risk Assessment Tool: The Archaeological Chinampas of Xochimilco}

\begin{abstract}
The development of the technology of unmanned aerial vehicles (UAV, drone) in the last decade has been vertiginous. Its use in the study of cultural heritage is growing and in this study we expose a workflow using an automated system of remote sensing by aerial photography through the use of a device that integrates a hexacopter to which two cameras have been adapted, one of them to obtain visible light (VIS) images, the other modified to capture the near infrared spectrum of light. We have taken as a case study a chinampa site in Xochimilco (El Japón) to evaluate its usefulness in the record and recognition of traits buried at shallow depth. By means of the photogrammetric processing of the stereopairs, the digital elevation model was generated to record a high resolution topography similar to that obtained through a LIDAR device, as well as other images in false color composition for the creation of standardized differential vegetation index (NDVI) maps that allow us to enhance archaeological features based on differences in growth and health of the vegetation .
\end{abstract}

Keywords: Drone, Cultural Heritage, Xochimilco

\footnotetext{
1 Instituto de Investigaciones Antropológicas, UNAM. acostaochoa@yahoo.com.mx

2 Instituto de Investigaciones Antropológicas, UNAM.

3 Instituto de Investigaciones Antropológicas, UNAM.

4 Posgrado en Antropología, UNAM.
} 
Sumario. 1. Introducción. La Cuenca de México y el patrimonio arqueológico en riesgo. 2. Las chinampas arqueológicas de la región Chalco-Xochimilco. 3. San Greogorio Atlapulco (El Japón). Un sitio chinampero. 4. La fotogrametría como herramienta de registro en Arqueología. 5. Técnicas de registro mediante dron. 6. Resultados y evaluación del estado actual del sitio. 7. Referencias.

\section{Introducción. La Cuenca de México y el patrimonio arqueológico en riesgo}

El crecimiento de la mancha urbana ha puesto en riesgo los sitios arqueológicos en la Ciudad de México y la zona chinampera de Xochimilco no es la excepción (Parsons 1989). En el caso de Xochimilco, a este problema debe añadirse el cambio en el uso de suelo de uno tradicionalmente agrícola, hacia uno habitacional y urbano. La zona chinampera de Xochimilco ha sido declarada Patrimonio Mundial desde 1986 (Figura 1), sin embargo actualmente se encuentra en riesgo de perder este estatus debido a la destrucción arqueológica, degradación ambiental y problemática de invasión de la mancha urbana. Esta es una razón importante para considerar a esta área de la ciudad de México como idónea para la aplicación de nuevas tecnologías orientadas a la investigación, registro y protección patrimonial. El estudio de caso que presentamos aquí, es el resultado de un proyecto de investigación arqueológica en el área chinampera del ejido de San Gregorio, Xochimilco, donde hemos aplicado de manera piloto un estudio fotogramétrico mediante el uso de un vehículo aéreo no tripulados (VANT) o dron, una metodología de registro desarrollada enteramente en el Instituto de Investigaciones Antropológicas de la UNAM como parte del proyecto «El desarrollo de las sociedades agrarias en la Cuenca de México», dirigido por Emily McClung y Guillermo Acosta, y orientado al estudio de las primeras aldeas agrarias de la Cuenca de México (Acosta y Jiménez 2014).

\section{Las chinampas arqueológicas de la región Chalco-Xochimilco}

Se ha sugerido la posibilidad de que el cultivo en chinampas se originase hacia los inicios del Posclásico Temprano, específicamente en los sitios del entorno lacustre de lago de Chalco. Armillas, en su obra ya clásica Jardines en los pantanos (Armillas 1971), planteaba su origen posiblemente en sitios como Xico, con una añeja tradición cultural y localizados en las orillas de una isla. Este planteamiento cobró eco en diversos investigadores, quienes estuvieron de acuerdo con Armillas sobre el origen sureño de las chinampas (Parsons 1971; Parsons et al. 1982a:174-175).

Estudios posteriores orientados a la identificación de sistemas agrícolas chinamperos originarios en la planicie lacustre, sin embargo, parecían destinados al fracaso (v.g. Ávila 1993; Parsons et al. 1982a). No aparecían evidencias de éstas supuestas chinampas en los sitios del periodo Azteca I, haciendo que algunos autores cambiaran de opinión rápidamente: no existen evidencias directas de que los habitantes de Xico, Chalco, Mixquic, Tláhuac, Culhuacán y Xochimilco practicaran el cultivo de chinampas en la planicie lacustre desde las épocas Azteca I y Azteca II. Sin embargo, la ubicación de estos sitios nucleares (particularmente las de Xico, Mixquic y Tláhuac), en los que poblaciones considerables se encontraban alejadas de terrenos bien drenados, es bastante sugestiva respecto a la posible existencia de cultivos limitados de chinampas. La escasez de sitios Azteca I y Azteca II en el lecho lacustre hace 


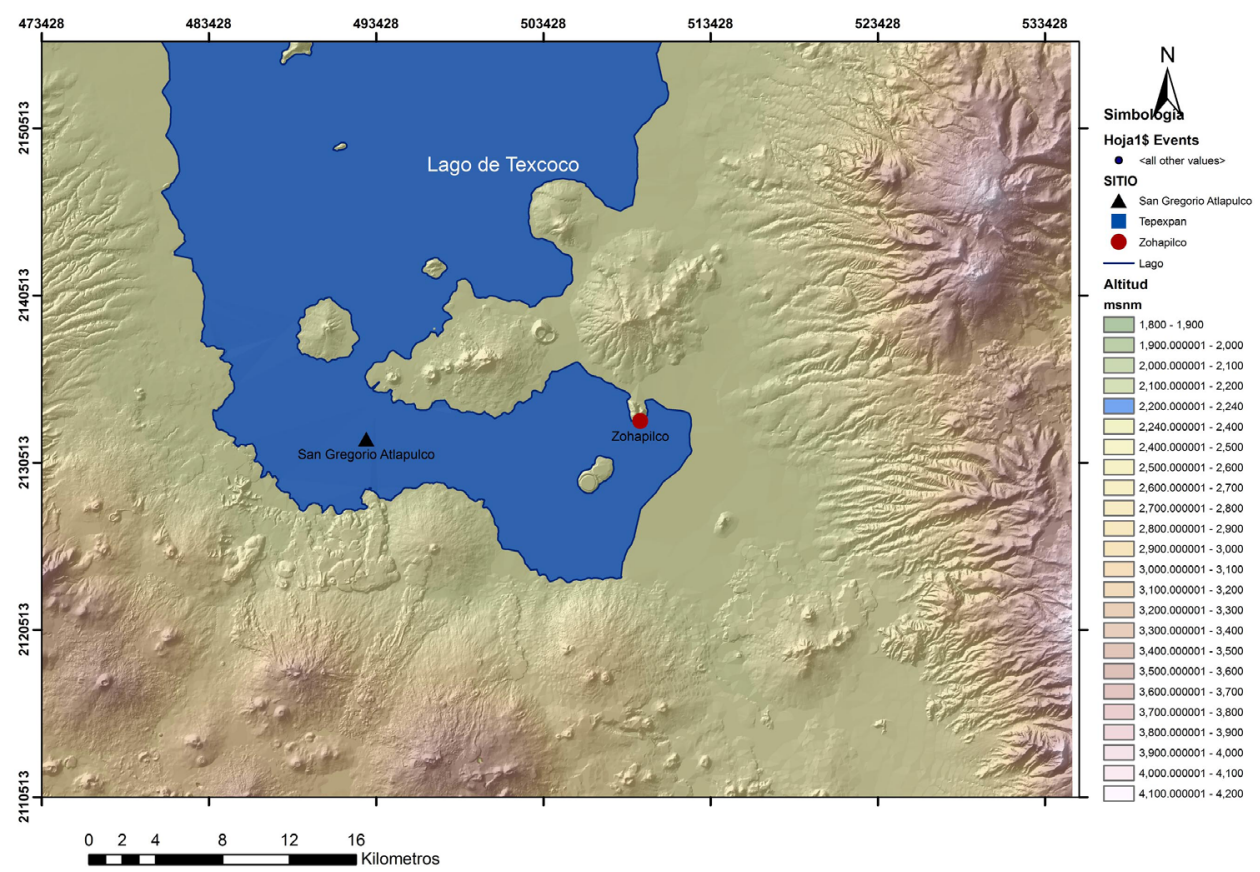

Figura 1. Ubicación del sitio arqueológico de San Gregorio Atlapulco al sur de la Cuenca de México (UTM, Datum WGS84).

pensar en una importancia muy limitada del cultivo de chinampas antes del siglo XV (Parsons 1992: 229).

Aunque las propiedades técnicas y de organización del trabajo para construir chinampas pueden tener antecedentes desde el Formativo, como se observa en el sistema constructivo de las plataformas de Terremote Tlaltenco (Serra 1988), su empleo para la intensificación agrícola es tardío. Es obvio que, de acuerdo a los sistemas constructivos del Posclásico Temprano (como las grandes plataformas habitacionales en Xico, Mixquic, Tláhuac o Chalco), las comunidades lacustres del Posclásico Temprano (ca.1150-1350) tenían ya los conocimientos de tecnología hidráulica para desarrollar sistemas chinamperos, sin embargo, su empleo hacia esta época no parece coincidir con los sitios del interior del lecho lacustre.

Todo parece indicar que el desarrollo intenso del modo de trabajo chinampero estuvo ligado con la construcción de las grandes obras hidráulicas de la Cuenca (como la calzada-dique de Tláhuac y otros), y posiblemente no fue extensivo sino hasta rebasado el siglo XIV. En todo caso, en periodos anteriores no se han localizado en sitios del interior del lago, sino en sitios cercanos de las orillas del lago y con mayor control a las inundaciones, como así parece indicar el descubrimiento de un sistema de plataformas y canales irregulares, identificado en Acatla-Tulyehualco como chinampas incipientes (véase Ávila 1999, Tomo III); o bien, en áreas con inundación controlada en zonas aluviales, como indica el hallazgo de dos chinampas en la zona de Ayotzingo (al suroriente de lago), con «cerámica Azteca asociada» ${ }^{5}$, y cuyos datos

\footnotetext{
5 Hodge (Hodge et al. 1996: 52) ubica el «Periodo Azteca» en 1150-1520 d.C., esto es, desde el Azteca I al Azteca III.
} 


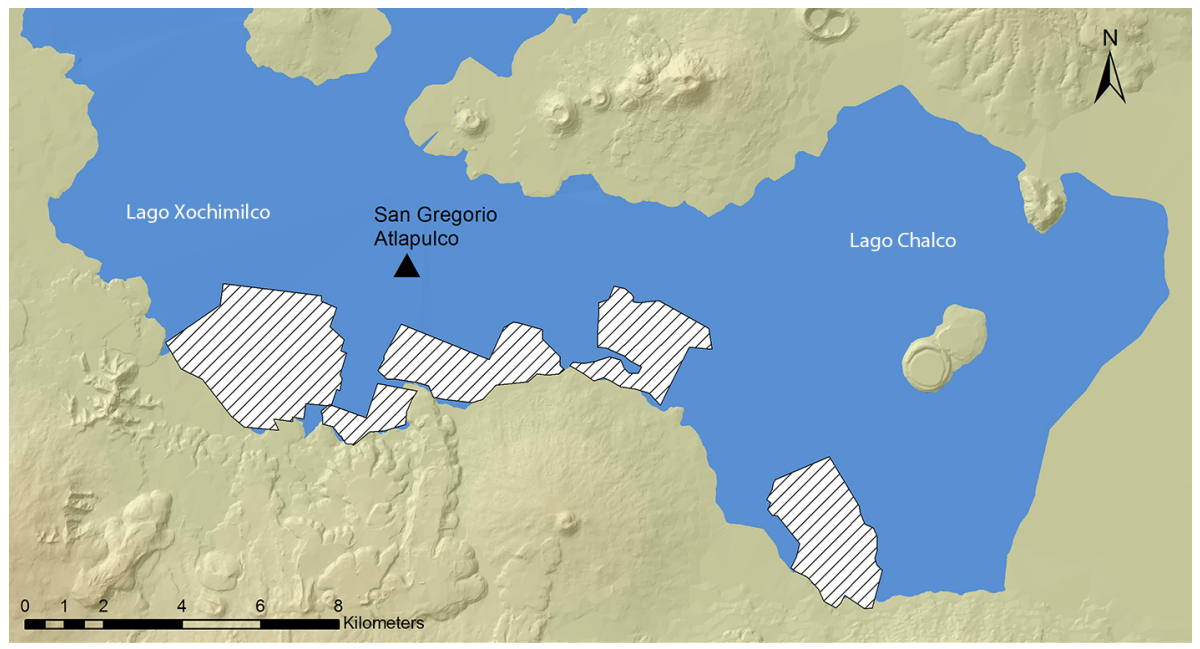

Figura 2. Ubicación de San Gregorio Atlapulco y zonas de producción chinampera post-Azteca (achurado) (Basado en Luna Golya 2014: 85).

de radiocarbono arrojaron fechas de $1210 \pm 50$, y $1280 \pm 90$ AP (Hodge et al. 1996: 62); así como en Xaltocan, al norte de la cuenca (Morehart y Frederick 2014), con dataciones centradas hacia el Posclásico Medio (1250-1350).

El estudio regional de Jeffrey Parsons en el área Chalco-Xochimilco (Parsons 1971, 1976, 1992; Parsons et al. 1982a, 1982b), ha permitido establecer que el periodo Posclásico Tardío (1350-1521) es el periodo de máxima expansión poblacional del sur de la Cuenca de México, y de proliferación de sitios en el lecho lacustre, que se encuentran claramente asociados a chinampas arqueológicas (Parsons et al. 1982b: mapa 36).

Un estudio reciente (Luna Golya 2014) ha logrado generar un catastro detallado de las chinampas arqueológicas, particularmente en Xochimilco, lo cual nos permite apreciar con más detalle la escala de la producción chinampera al momento del contacto (Figura 2). Desgraciadamente, estas chinampas, registradas en fotografías aéreas de la primera mitad del siglo XX, se han perdido en su mayoría por distintos procesos naturales y humanos. La de San Gregorio Atlapulco es uno de estos casos.

\section{San Gregorio Atlapulco (EI Japón), un sitio chinampero}

El sitio arqueológico El Japón, en San Gregorio Atlapulco (Xochimilco, D.F.), es una aldea chinampera del Posclásico Tardío e inicios de la Colonia que ha sido impactada por procesos humanos y su destrucción parcial ha disminuido los rasgos visibles en superficie, tanto de la plataforma habitacional, como de las chinampas arqueológicas circundantes. Este sitio arqueológico fue reportado en el estudio regional de Parsons y colegas (Parsons et al., 1982a, 1985) quienes realizan el primer plano del sitio y sondeos en uno de los montículos de la plataforma (Figura 3), donde localizan por primera vez restos humanos y determinan una ocupación de finales del periodo Azteca que se continúa a inicios de la Colonia (Parsons et al. 1982b). 


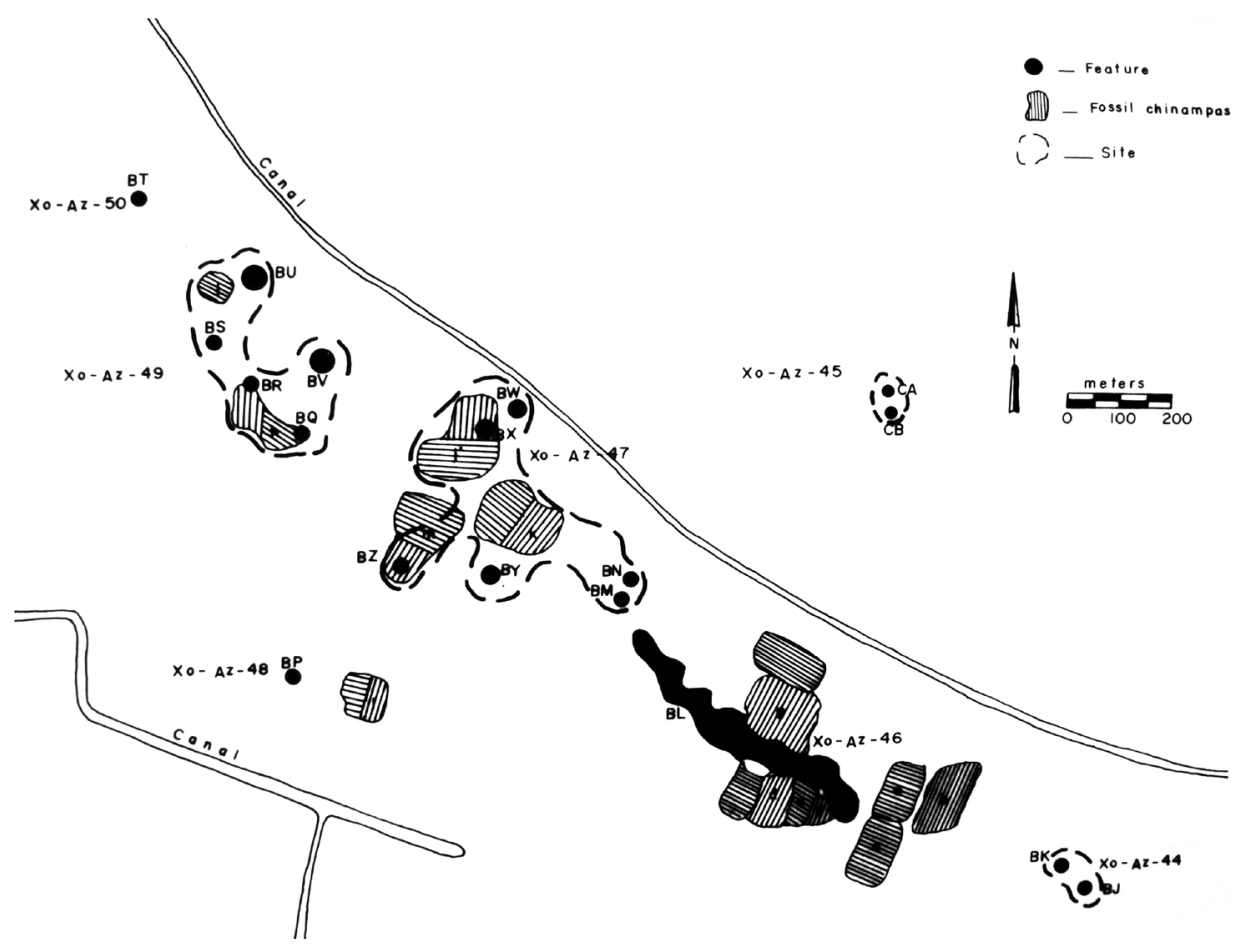

Figura 3. Plano del sitio realizado por Jeffrey Parsons y asentamientos aledaños (Parsons et al. 1982a: fig. 35).

Más tarde, Martha Lechuga (1977) realiza una topografía más detallada de la plataforma habitacional (aunque las chinampas no son registradas a detalle) y realiza recolección de cerámica de superficie. Hasta ese momento, el sitio y sus chinampas parecían estar bien conservados, tal y como se nota en la fotografía aérea de 1975 que presentamos en la Figura 4. Posteriormente, en 1988, Carlos González inicia un proyecto en el sitio con el fin de «...profundizar en el análisis de los procesos de trabajo relacionados con el cultivo de chinampas, así como en el modo de vida de los agricultores que los desarrollaban. Para lograrlo se propuso el rescate y estudio de los elementos materiales que constituyen sus indicadores potenciales» (González 1996: 83). El estudio de Carlos González se centró en la zona occidental del sitio donde se excavaron diversas estructuras que corresponden a ocupaciones del Posclásico Tardío e inicios de la Colonia, no obstante, también se realizó un mapa detallado del sitio el cual cubrió 64 hectáreas y localizó 32 montículos y unas 30 parcelas de chinampas (Figura 4).

En 1990 el ejido de San Gregorio fue objeto de un salvamento arqueológico a cargo de Raúl Ávila López (1995), efectuado a causa de las obras de construcción de un distrito de riego, y tras la destrucción de casi el 90\% de los montículos arqueológicos. En este estudio se excavaron los restos de la plataforma principal del sitio que integra los sitios designados como Xo-Az-47, Xo-Az-46, y Xo-Az-44 por Parsons et al. (1982a: 9) (Figuras 5 y 6). Ávila pudo identificar VI capas, de las cuales las últimas dos representaban la ocupación precerámica, mencionando que entre los restos de este periodo se localizaron fragmentos pequeños y grandes de huesos 


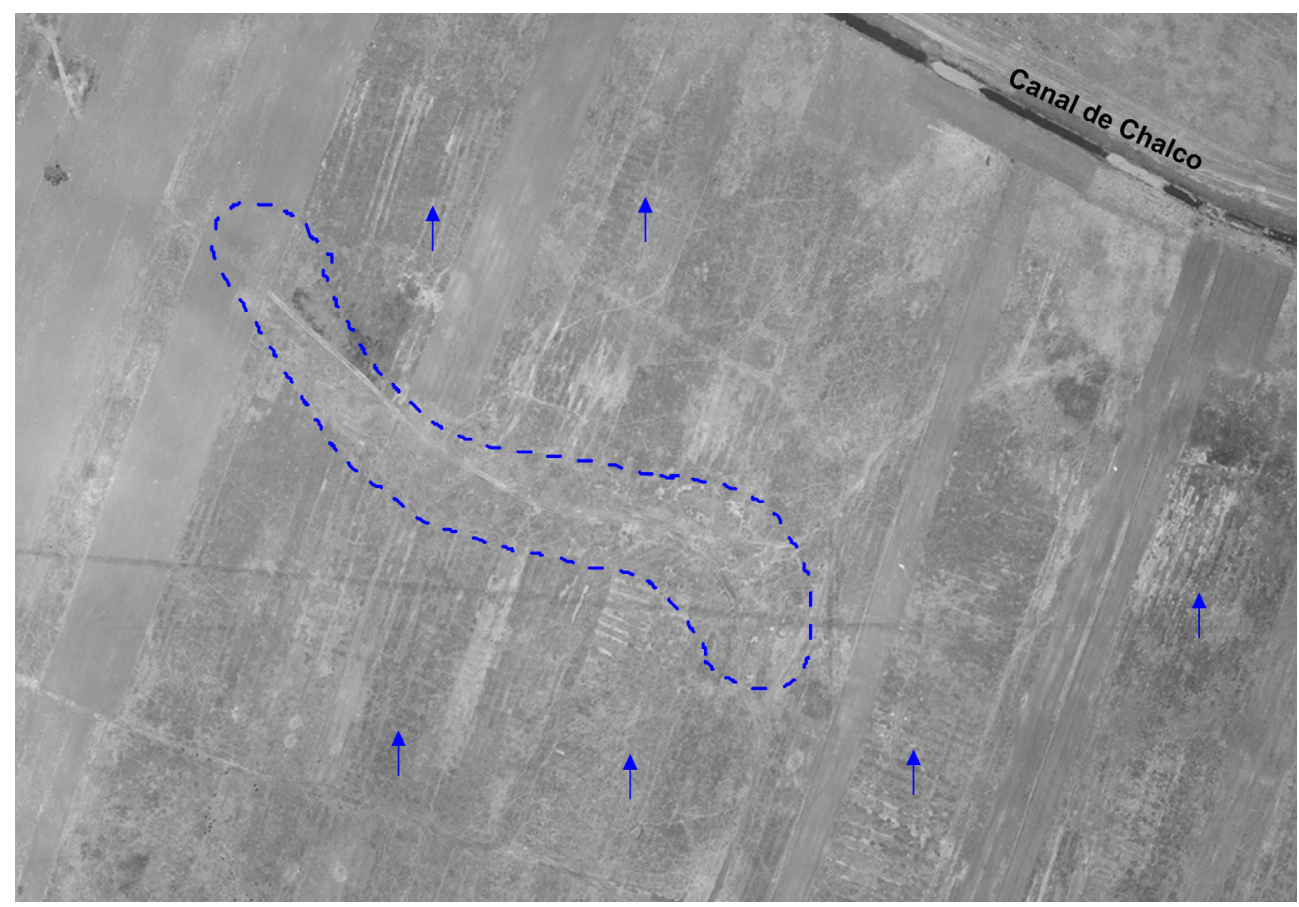

Figura 4. Fotografía aérea de 1975, donde se observa el sitio antes del impacto moderno (CETENAL); la línea de trazos marca el límite aproximado de la plataforma y las flechas indican chinampas arqueológicas.

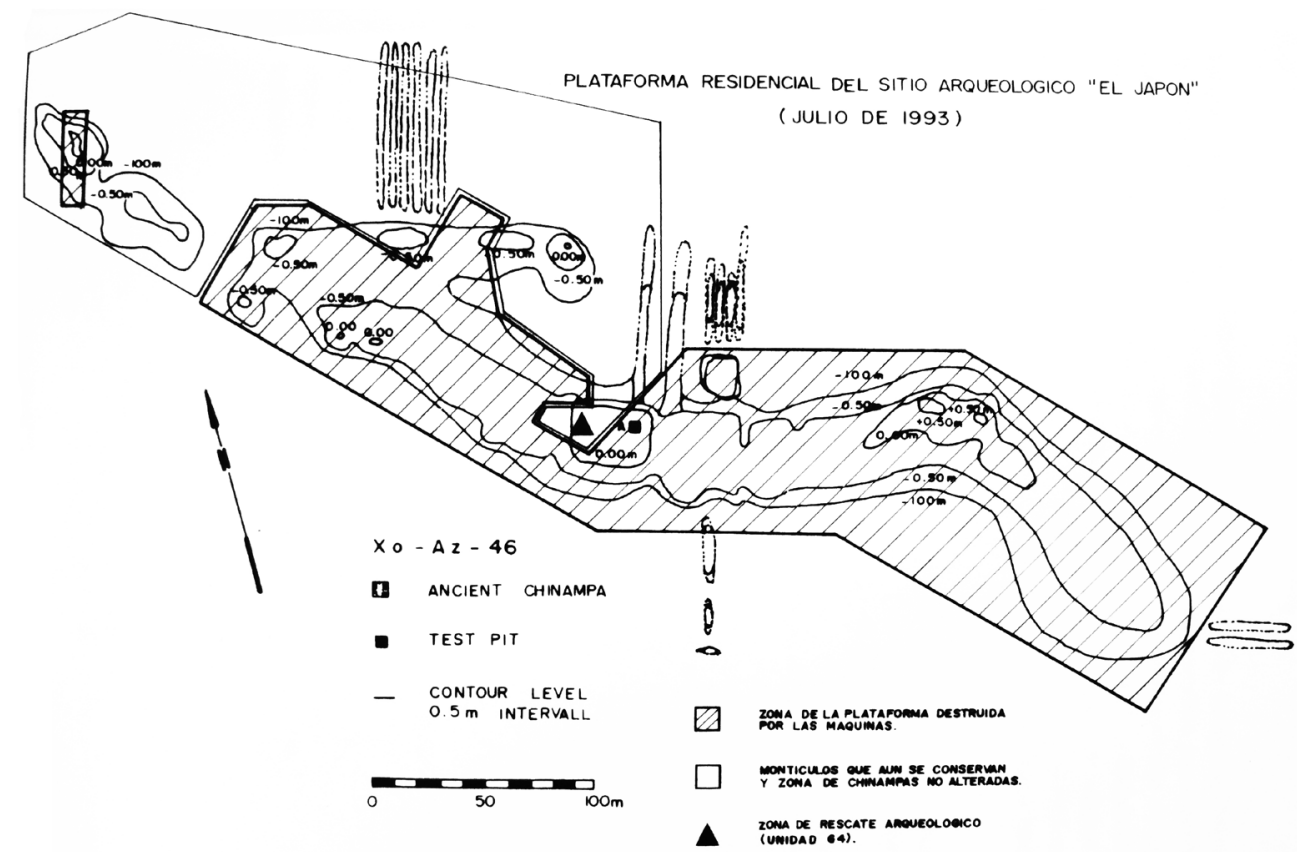

Figura 5. Área de las excavaciones realizadas por Raúl Ávila (Unidad 64) y zona de nivelación de la plataforma por las máquinas (achurado) (Ávila 1995). 
Figura 6. Restos de la plataforma principal destruida en 1993.

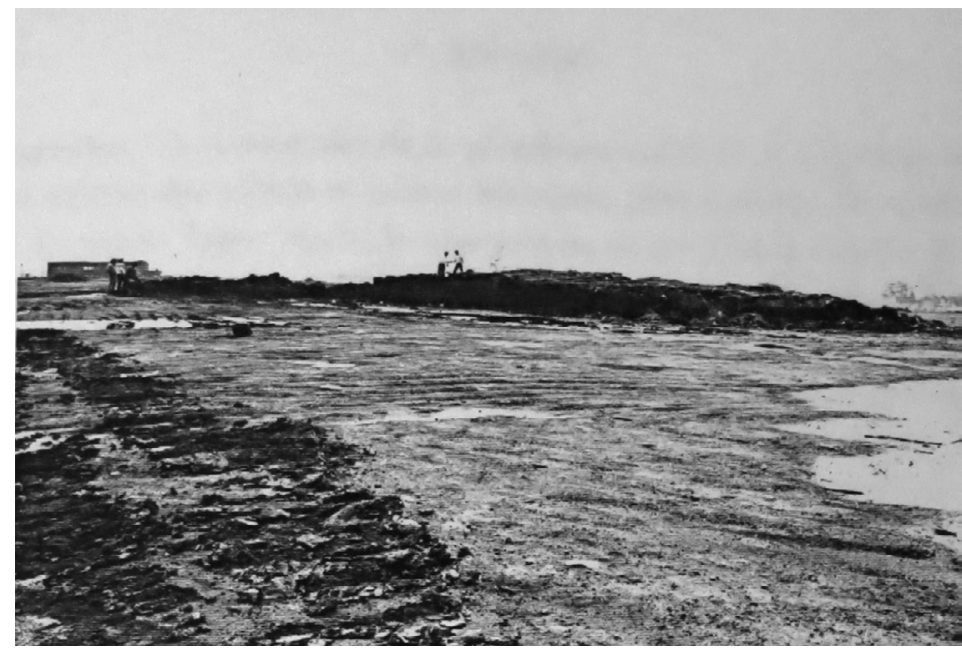

de animales, caparazones de tortuga y semillas junto con piedras de molienda de basalto asociados a restos de hogares, y abundantes artefactos de obsidiana gris. De acuerdo con este autor, la «cronología relativa, en base al instrumental lítico, se sitúa aproximadamente entre el 2500aC y 2000aC» (Ávila 1995: 270). Desgraciadamente, los resultados presentados en el informe final del sitio no incluyen dataciones de radiocarbono o estudios botánicos y zooarqueológicos detallados, por lo que se consideró necesario investigar con más detalle este importante sitio (Acosta et al. 2012). De esta manera, En julio de 2013 el Instituto de Investigaciones Antropológicas de la UNAM inició un estudio de las ocupaciones asociadas al periodo de agricultura temprana en el área el cual incluye el registro detallado del sitio y sus chinampas arqueológicas.

Entre los meses de junio y agosto se llevó a cabo la topografía y estudio fotogramétrico de sitio, para posteriormente iniciar las excavaciones sistemáticas en dos unidades asociadas a la ocupación precerámica del sitio. El primer objetivo de este trabajo de registro de superficie fue tener una idea más clara de las condiciones actuales del sitio, y contrastarlo con los registros previos para evaluar su deterioro. Esta primera etapa incluyó la visita a la Dirección de Registro de Monumentos Públicos y Zonas Arqueológicas del INAH, donde nos percatamos de que, a pesar del avanzado grado de destrucción del sitio, éste cuenta con una poligonal de protección generada como resultado de registro del sitio por Carlos González, la cual desgraciadamente ha resultado obsoleta en cuanto a los fines de proteger los rasgos arqueológicos, pues como lo menciona el mismo autor (González 1996), la plataforma prehispánica fue prácticamente arrasada en 1991 tras la nivelación de los rasgos para la creación de un distrito de riego, el cual nunca fue concluido. Los restos de esta plataforma corresponden al área excavada posteriormente en el salvamento realizado por Raúl Ávila un año más tarde (Figura 7). 


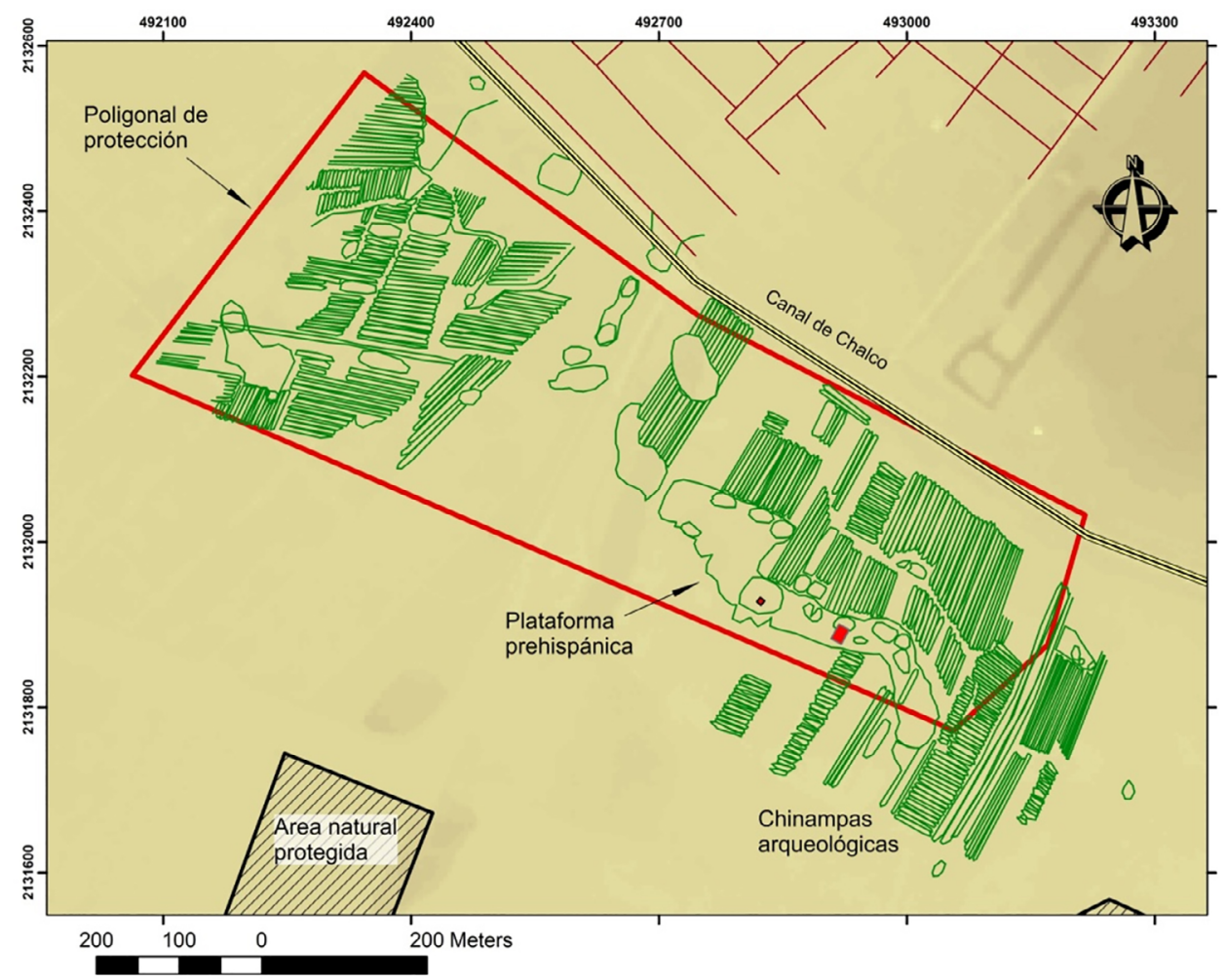

Figura 7. Elementos arqueológicos de San Gregorio Atlapulco registrados por Carlos J. González (1996: 82) y poligonal de protección del sitio (rojo) transformados a coordenadas UTM, Datum WGS84.

\section{La fotogrametría como herramienta de registro en Arqueología}

La fotogrametría puede definirse como la técnica cuyo objeto es estudiar y definir con precisión la forma, dimensiones y posición en el espacio de un objeto cualquiera utilizando esencialmente medidas hechas sobre una o varias fotografías (Clavo 1985). Aunque la fotogrametría analógica es tan antigua como la fotografía misma, actualmente las computadoras nos permiten el tratamiento digital de las imágenes con un ahorro de tiempo y aumento en la capacidad de procesamiento. El análisis fotogramétrico computarizado permite obtener nubes de puntos que sirven para generar archivos similares a los creados en un sistema LIDAR, y poder procesarlos como tales. Otra ventaja al obtener nubes de puntos es que estos pueden utilizarse para crear una malla $3 \mathrm{D}$ de alta resolución, la cual conserva los datos de los pixeles a los que se asocia cada punto en coordenadas X, Y y Z, y con ello generar modelos 3D que incluyen una textura de alta resolución. Estos modelos 3D permiten una mejor visualización, además de servir como medios visuales óptimos para la divulgación científica (Acosta y Jiménez 2014). La fotogrametría fue principalmente aplicada en la arquitectura durante varias décadas, hoy su uso se ha diversificado con el desarrollo de los sistemas de escaneo láser y fotogrametría digital, aplicándose de manera 
más frecuente en la realización de modelos digitales de terreno o modelado 3D. En la actualidad, el registro fotogramétrico se ha convertido en una técnica de registro básica para el arqueólogo y su empleo abarca desde el modelado 3D de objetos arqueológicos, hasta el registro topográfico de sitios arqueológicos (Lerma et al. 2010).

\section{Técnicas de registro mediante dron}

\subsection{Los drones}

En la última década, el empleo de vehículos aéreos no tripulados (mejor conocidos como drones o UAV's - unmanned aerial vehicles - por sus siglas en inglés:) en usos no militares es cada vez más recurrente. Particularmente, el desarrollo de aplicaciones asociadas a la investigación científica, como pueden ser el reconocimiento del terreno o la teledetección. Aunque su aplicación en la arqueología aún es limitada, su potencial empleo para la fotografía aérea cobra mayor importancia al reducirse su costo. En un estudio previo hemos expuesto las ventajas en el empleo de un dron al que se le ha adaptado un equipo automatizado de fotografía de alta resolución con la finalidad de realizar secuencias fotográficas que son posteriormente procesadas mediante técnicas fotogramétricas para realizar, desde fotografías aéreas individuales (cenitales y oblicuas) para la identificación de rasgos no visibles desde el terreno, hasta el uso de estereopares procesados digitalmente para obtener verdaderas ortofotografías, modelos digitales de elevación (OEM) y modelos 3D del terreno que integran texturas de alta resolución (Acosta 2014; Acosta y Jiménez 2014). Al inicio de nuestros trabajos, se empleó un dron de baja capacidad (tetracóptero, DJI Phantom), el cual presenta la ventaja de un bajo coso (menos de mil dólares) pero también estableció las limitaciones impuestas por esa baja capacidad (limitado a una cámara compacta, alcance menor a $300 \mathrm{~m}$ y autonomía de vuelo de no más de 7 minutos).

Para poder desarrollar un sistema más eficiente de vuelo, fue necesaria la adquisición de un equipo aéreo de mayor capacidad (hexacóptero, DJI S1000, Figura 8) el cual además es susceptible de ser modificado para integrar un módulo que permite la programación de un plan de vuelo controlado a partir de una computadora (Ground Station), así como el monitoreo de las condiciones del vuelo como el nivel de batería, altitud, velocidad de desplazamiento horizontal y vertical, entre otros

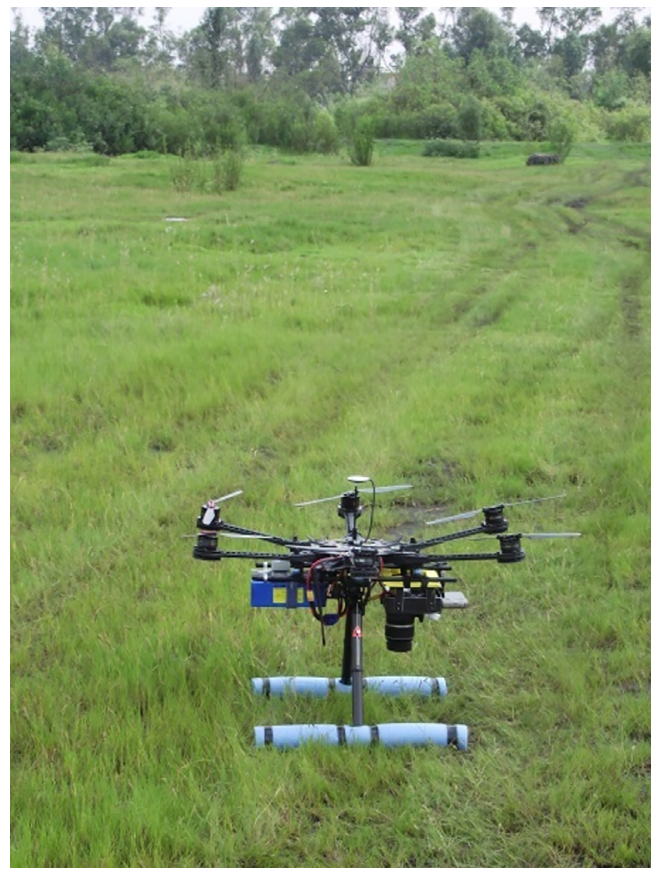

Figura 8. Equipo de fotogrametría automatizada «Tótec II». 
parámetros. Este equipo permite realizar la fotogrametría de áreas extensas abarcando sitios arqueológicos completos, mediante la programación en la PC del área a fotografiar.

\subsection{El sistema fotográfico}

Para el estudio de los rasgos visibles en superficie se desarrolló un sistema automatizado de registro por fotografía aérea mediante el uso de un dron al cual se le han adaptado dos cámaras fotográficas, una de ellas para obtener imágenes de luz visible (VIS), y otra modificada para captar un espectro más amplio, desde ultravioleta (UV) hasta infrarrojo cercano (NIR). Mediante el empleo de un filtro azul (wratten 47) se bloquea el espectro UV y la luz visible, (NIR=0.75-1.4 $\mu \mathrm{m})$. Ambas cámaras han sido «hackeadas», con la finalidad de modificar el firmware y añadir un script, que incluye un intervalómetro que obtura cada 2 segundos. Esto permite que la cámara obtenga de manera automatizada imágenes a intervalos regulares sin la necesidad de añadir otro disparador externo. Una vez obtenidas las secuencias fotográficas, tanto en luz visible como en infrarroja, estas se procesan por separado para obtener dos ortofotografías de muy alta resolución $(3 \mathrm{~cm}$ por pixel en una imagen que abarca 25 hectáreas) (Figura 9).

Con el procesamiento fotogramétrico de los estereopares es posible generar: a) un mosaico ortorrectificado de las imágenes aéreas de luz visible a una gran resolución (Figura 9A); b) un modelo digital de elevación y de terreno que permite procesarse como sombreado digital que registra una topografía de alta resolución similar a la obtenida mediante un LIDAR (Figura 9B); y c) una imagen en composición de falso color (Figura 9C) que permite realizar otros análisis más especializados como el índice de vegetación diferencial normalizada (NDVI) que resalta rasgos arqueológicos con base en diferencias del crecimiento y vigor de la vegetación (Figura 9D).

\section{Resultados y evaluación del estado actual del sitio}

Durante el análisis fotogramétrico de los rasgos en superficie de San Gregorio, el trabajo se centró en los remanentes de una plataforma del periodo Azteca. En base al registro de superficie y mapeo fotogramétrico, podemos decir que el sitio arqueológico se encuentra alterado casi en su totalidad, no obstante, la fotogrametría de las chinampas permite generar una microtopografía que registra los elementos con un nivel que sería difícil conseguir incluso con una estación total. Por otro lado, como se puede observar en la secuencia de la Figura 9, también fue posible resaltar los rasgos de canales y chinampas mediante el registro con cámara infrarroja en áreas niveladas por la construcción del distrito de riego y que no se advertían en la ortofoto a color. De esta manera, esta metodología ha permitido recuperar información que se creía perdida, así como definir mejor la extensión y estructura interna de las chinampas arqueológicas, incluso registrar la extensión original de chinampas cuyos rasgos en superficie no son observables debido a la nivelación moderna del terreno. Esta metodología también puede aplicarse a otro tipo de sitios arqueológicos como pueden ser sitios monumentales o de áreas domésticas.

Los resultados aquí presentados, aunque perfectibles considerando que es la primera aproximación de este tipo en México, pueden considerarse prometedores si 

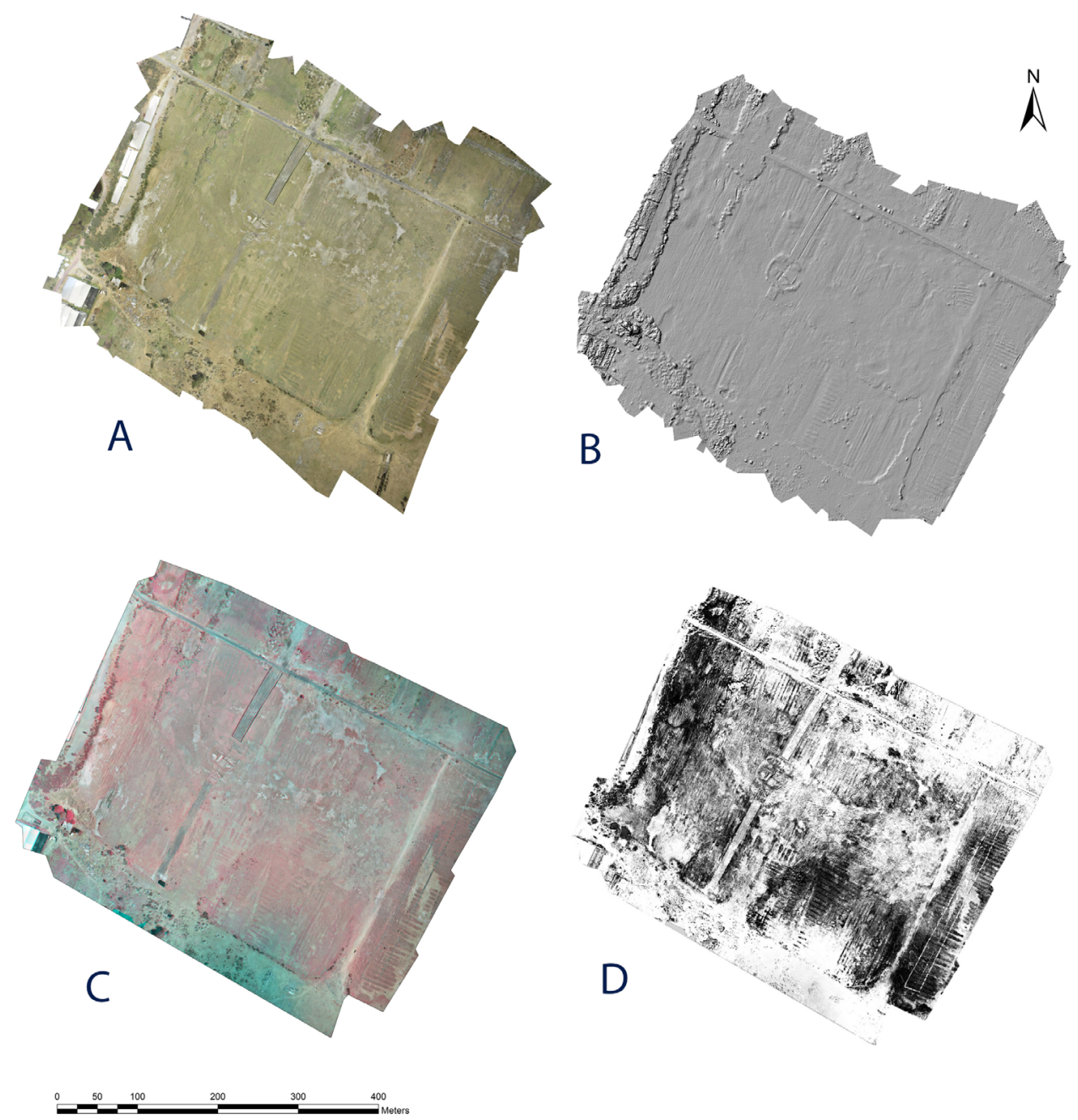

Figura 9. Ortofotografías resultado del análisis fotogramétrico: A) Luz Visible (VIS), B) Sombreado digital con base en el Modelo Digital del Terreno (MDT, DEM), C) Falso Color resultado de la fusión de imagen de luz visible e infrarrojo cercano (NIR), D) Rasgos resaltados mediante el análisis de Índice Normalizado de Vegetación Diferencial (NDVI) del infrarrojo cercano (con histograma estrechado).

consideramos los costos de imágenes satelitales de alta resolución ( $3 \mathrm{~m}$ por pixel) de sensores como GeoEye, los cuales integran bandas en pancromático e infrarrojo cercano. Por otro lado, la resolución de los sensores solo permite resaltar rasgos con un nivel de resolución muy bajo en el caso de estructuras domésticas, por lo que su uso sigue siendo a un nivel más regional o enfocado a sitios monumentales (Lasaponara et al. 2012). Nuestro proyecto contempla la incorporación de una cámara termográfica al dron, lo cual permitiría resaltar otros elementos arquitectónicos o rasgos enterrados basados ya no solo en el calor reflejado (basado en diferencias de vegetación), 
como es el caso del infrarrojo, sino también observable como calor emitido, como en el caso de áreas desprovistas de vegetación con presencia de estructuras enterradas.

Como puede advertirse, la fotogrametría y el empleo de drones en arqueología es, aunque incipiente, un campo de estudio muy prometedor para la investigación del Patrimonio Cultural.

Agradecimientos: Esta investigación se ha realizado con la ayuda del Programa de Apoyo a Proyectos de Investigación e Innovación Tecnológica (PAPIIT IG400513) y del Consejo Nacional de Ciencia y tecnología (Conacyt 253664). Agradecemos las facilidades otorgadas por la comunidad de San Gregorio Atlapulco en la realización del estudio.

\section{Referencias}

Acosta, Guillermo

2014 «El empleo de fotografía aérea a baja altitud mediante UAV en el registro fotogramétrico 3D de sitios arqueológicos». Ponencia presentada en el III Coloquio Interno del Instituto de Investigaciones Antropológicas, UNAM. México.

AcosTA, Guillermo y Gerardo JimÉNEZ

2014 «La fotogrametría digital mediante dron como alternativa en el registro topográfico de sitios arqueológicos». Ponencia presentada en el IV Coloquio Internacional de Arqueometría Instituto de Investigaciones Antropológicas, UNAM. México.

Acosta, Guillermo, Patricia Pérez y Joaquín Arroyo

2012 Proyecto Poblamiento, Agricultura Inicial y Sociedades Aldeanas en la Cuenca de México. Proyecto remitido al Consejo de Arqueología del INAH, México.

Armilllas, Pedro

1971 «Gardens on Swamps». Science 174 (4010): 653-661.

Ávila LóPEz, Raúl

1993 La ocupación del espacio lacustre: Investigaciones del Proyecto Salvamento Arqueológico Xochimilco. Informe Técnico, INAH, Subdirección de Salvamento Arqueológico. México.

1995 Excavaciones arqueológicas en San Gregorio Atlapulco, Xochimilco. Informe entregado la Dirección de Salvamento Arqueológico del INAH, México.

1999 Investigaciones arqueológicas en San Luis Tlaxialtemalco. Tomos I-VI. México: Dirección de Salvamento Arqueológico-Sumitomo Corporation.

Clavo, Luis Domingo

1985 Apuntes de fotogrametría. Madrid: Universidad Politécnica de Madrid. Escuela Universitaria de Ingeniería Técnica Topográfica.

GonzÁlez, Carlos Javier

1996 «Investigaciones arqueológicas en 'El Japón’: sitio chinampero en Xochimilco». Arqueología 16: 81-93.

Hodge, Mary G., Carlos Córdova y Charles D. Frederick

1996 «Los asentamientos prehispánicos y el medio cambiante del sureste de la Cuenca de México», en Tierra, agua y bosques. Historia y medio ambiente en el México 
central, Alejandro Tortolero, ed., pp. 49-68. México: CEMCA/UDG/Instituto de Investigaciones Luis Mora

LASAPONARA, Rosa y Nicola MASINI, eds.

2012 Satellite Remote Sensing: A New Tool for Archaeology. Heidelberg: Springer-Verlag.

Lechuga Solís, Martha Graciela

1977 Análisis de un elemento de la estructura económica azteca: la chinampa. Tesis de Maestría en Arqueología. Escuela Nacional de Antropología e Historia, UNAM. México.

Lerma, José, Santiago NaVArro, Miriam Cabrelles y Valentín VillaVerde

2010 «Terrestrial Laser Scanning and Close Range Photogrammetry for 3D Archaeological Documentation: The Upper Palaeolithic Cave of Parpalló as a Case Study». Journal of Archaeological Science 37 (3): 499 -507.

LunA Golya, Gregory Gerard

2014 Modeling the Aztec Agricultural Waterscape of Lake Xochimilco: A GIS Analysis of Lakebed Chinampas and Settlement. Tesis doctoral, Department of Anthropology, The Pennsylvania State University, University Park.

Morehart, Christopher T. y Charles D. Frederick

2014 «The Chronology and Collapse of pre-Aztec Raised Field (Chinampa) Agriculture in the Northern Basin of Mexico». Antiquity 88 (340): 531-548.

PARSONS, Jeffrey R.

1971 Prehispanic Settlement Patterns in the Chalco Region, México. Memoirs of the Museum of Anthropology 3. Ann Arbor: University of Michigan.

1976 «Settlement and Population History of the Basin of México», en The Valley of México, Eric R. Wolf, ed., pp. 69-100. Albuquerque: University of New Mexico Press.

1989 «Arqueología regional en la Cuenca de México: Una estrategia para la investigación futura». Anales de Antropología 26 (1): 157- 257.

1992 «El papel de la agricultura chinampera en el abasto alimenticio de Tenochtitlan», en Chinampas prehispánicas, Carlos J. González, comp., pp. 207-244. México: Instituto Nacional de Antropología e Historia.

Parsons, Jeffrey, Elizabeth Brumfiel, Mary H. Parsons y David WiLson

1982a Prehispanic Settlement Patterns in the Southern Valley of México, Chalco-Xochimilco Region. Memoirs of the Museum of Anthropology 14. Ann Arbor: University of Michigan.

1982b La agricultura chinampera del periodo Prehispánico Tardio en el lago Chalco-Xochimilco, México. Informe Técnico dirigido al Instituto Nacional de Antropología e Historia y a la National Science Foundation.

Parson, Jeffrey R., Mary H. PArson, Virginia Popper y Mary TAFT

1985 «Chinampa Agriculture an Aztec Urbanization in the Valley of Mexico», en Prehistoric Intensive Agriculture in the Tropics, Ian S. Farrington, ed., pp. 49-96. Oxford: BAR International Series 232.

Serra Puche, Mari Carmen

1988 Los recursos lacustres de la Cuenca de México durante el Formativo. México: Instituto de Investigaciones Antropológicas. UNAM. 